\title{
Recrear una conciencia social: Reciclar/reapropiar la moda en Loco afán: crónicas de sidario de Pedro Lemebel
}

Recreating Social Conscience: Recycling/Reappropriating Fashion in Pedro Lemebel's Loco afán

\author{
Stephanie N. Saunders \\ Capital University \\ ssaunde2@capital.edu
}

En medio de la transición a la democracia, el escritor y artista visual Pedro Lemebel comenzó a forjar un espacio dialéctico para reflexionar sobre las privaciones causadas por la debilitadora afección del SIDA. En su crónica urbana Loco afán: crónicas de sidario (1996), el autor presta atención especial a las apariencias físicas que señalan no solo la salud física de los personajes, sino que destacan el estado actual y futuro del país. En dicha obra, la innegable importancia de la moda, tratada con un detalle meticuloso, destaca el creciente poder del mercado neoliberal y la globalización en cuanto a la identidad nacional. En este artículo, implementando las teorías de los estudios de la moda, analizaré cómo las representaciones de la moda -específicamente las reapropiaciones o reciclaje de ella- cultivan una conciencia social, no solo para la realidad frecuentemente ignorada del SIDA, sino también del estado actual de la sociedad chilena.

Palabras clave: Literatura chilena, cuerpo, moda, SIDA.

In the midst of the Chile's Transition to democracy, writer and visual artist Peter Lemebel forged a dialectical space that encouraged reflection on the hardships caused by AIDS, an illness often considered taboo during the dictatorship. In Loco afán: crónicas de sidario (1996) the author pays special attention to physical appearances, a corporal barometer indicating not only the physical health of the characters but also highlighting the current and future states of the nation. In Loco afán, the undeniable importance of fashion, treated with meticulous detail, exonerates the growing market power of neoliberal globalization in terms of national identity. This article, through the implementation of fashion studies, will analyze how the representations of fashion specifically in terms of reappropriations or recycling-cultivate a social conscience, for both the often ignored reality of AIDS, as well as the current state of Chilean society.

Keywords: Chilean Literature, Body, Fashion, AIDS. 
Durante el último fin de semana de mayo del 2011, Santiago de Chile bulle con su caótica energía otoñal que espera con anticipación el invierno, como si a través de ella se pudiese abrigar a sí misma en un chaleco provocador y hogareño. Como suele ocurrir en dicho centro metropolitano hay una plétora de actividades aparentemente contradictorias: mientras unos doce mil manifestantes protestan de manera pacífica en contra de HidroAysén, un polémico proyecto multimillonario que, a pesar del severo impacto medioambiental, promete responder a las crecientes necesidades eléctricas del país, unos dieciséis mil asistentes en total pasan por el Parque Arauco, uno de los epicentros de la moda capitalina, para asistir el estreno del primer evento "Ropero de Paula", que reúne diversas propuestas de talleres de costura, puestos de numerosas boutiques y desfiles de diseñadores nacionales e internacionales. Sin embargo, el discurso de la conservación de la naturaleza no se quedó solo en la esfera pública, o sea, en las manifestaciones ubicadas en la Alameda. En la esfera semiprivada del Ropero, cuya entrada valía unos 4.000 pesos chilenos, se sugirió el tema de la conservación creativa. En particular esto aconteció en la charla de "12 na", un conjunto de diseñadores argentinos que se especializan, según su propia descripción, en "un proyecto artístico de reciclado textil" (http://www.12-na.com.ar/). Ellos encarnan sin tapujos el gran fenómeno de la reapropiación de "doceñar" que marca la moda, una industria que se esfuerza por una producción, destrucción y reproducción constante.

En este ciclo agitado, que pretende generar una gama de nuevos looks, al menos al ritmo estacional y de una manera nacional y global, el crecimiento de la industria de la indumentaria se destaca, para varios filósofos como Lars Svendsen, como uno de los eventos más decidores en la historia que marca la dirección hacia la modernidad (23). Dicha "progresión" requiere de un diálogo constante con el pasado y el presente porque la moda, por muy innovadora que sea, se mantiene copiadora a la vez, y con frecuencia nos invade con una sensación de nostalgia. El mundo de la costura nos recuerda simultáneamente los límites de una posmodernidad plural: a pesar de la variedad de estilos que se pueden encontrar en el Santiago del siglo veintiuno, el hecho de que una prenda implique una categorización de identidad, delimita la fluidez de la autoexpresión.

Un destacado escritor y artista visual, Pedro Lemebel, cuyo papel clave se celebra como innegable en cuanto al proceso de la transición a la democracia en Chile, juega con estos múltiples significados de la moda para cultivar una conciencia social a nivel de género, sexualidad e incluso identidad neoliberal. Para elaborar este discurso provocador que favorece una experiencia visual incluso al nivel de la lectura, en este estudio analizaremos cómo las representaciones de la moda en Loco afán: crónicas de sidario (1996) desarrollan una conciencia social, no solo para la realidad frecuentemente ignorada del SIDA, sino también en cuanto al estado actual de la sociedad chilena ${ }^{1}$. Nos concentraremos específicamente en las reapropiaciones o reciclaje de la moda

\footnotetext{
1 Anotamos que la representación de la moda se encuentra en varias partes de la obra de Lemebel. Véase la obra crítica de Reinas del otro cielo: modernidad y autoritarismo en la otra de Pedro Lemebel para otras referencias. Se recomienda consultar a Ángeles Mateo del Pino para una profundización del título (227).
} 
en tres partes: el movimiento del eje del discurso a la nación estadounidense, creando una dialéctica a la vez periférica y centrífuga que aluza las gravedades eminentes del SIDA, la reapropiación de ropa usada entre las "locas", y, finalmente, la rica creatividad de ellas en cuanto al diseño y la innovación.

El tercer libro de Lemebel, Loco afán, publicado en plena transición a la democracia, titila el interés del lector con sus imágenes humorísticas, tejiéndolas no tan sutilmente con la abyecta realidad de una enfermedad debilitadora. A la vez, cabe destacar que el mismo autor no se mantuvo como el único que implementaba la hipérbole para impactar a su público. Otros tipos de exageraciones se manifiestan en el discurso público al tratar esta afección. Por ejemplo, en enero de 1987 la popular revista de mujeres Paula empezó el año con un reportaje del SIDA, destacando que Chile mantuvo el cuarto lugar en Sudamérica en cuanto a número de enfermos, siendo los homosexuales el grupo de mayor riesgo (Torres Cautivo 67). Según el artículo, "Se cree que la promiscuidad de las relaciones homosexuales podría favorecer la infección con SIDA. En un lapso de 20 años un homosexual tiene como promedio mil pares diferentes" (69). Esta clara ponderación refleja el tabú que envolvía a la enfermedad asociada con las comunidades homosexuales y travestis en la sociedad chilena durante el régimen militar y a comienzos de la transición a la democracia. Descosiendo esta costura apretada de los años del régimen militar, Pedro Lemebel comenzó a forjar un espacio dialéctico para reflexionar sobre las privaciones causadas por esta enfermedad crónicamente debilitadora en Loco afán, donde las apariencias físicas señalan no solo la salud de los personajes, sino que destacan el estado actual y futuro del país. Así la palmaria importancia de la moda, tratada con un detalle meticuloso, exonera el creciente poder del mercado neoliberal y la globalización en cuanto a la identidad nacional.

Antes de sumergirnos en el discurso de la reapropiación-reciclaje indumentario, nos resulta alumbrador explorar el papel fundamental de la moda que se resalta desde la primera crónica de la obra, "La noche de los visones". En esta se destaca la precisa intersección entre la moda, como una metonimia del estado neoliberal de la nación, y el metafórico estado del SIDA. "La noche" pormenoriza el encuentro de las rotas y regias con ricos contrastes de la moda, con las últimas vacilando en cuanto a la elección del vestuario: "Que la camisa de vuelos, que el cinturón Saint Tropez, que los pantalones rayados, no mejor los anchos y plisados con maxifalda, con zuecos y encima tapados de visón [...]" (12). Estas figuras y sus ilusiones confluyen en la esfera pública con debut cinematográfico: "El barrio se despobló para verlas, a ellas tan sofisticadas como estrellas de cine, como modelos de la revista Paula" (13). La referencia a la revista de mujeres Paula contiene la performance de la alta costura de las regias a nivel nacional, en contraste directo con la expansión global que notaremos más tarde. Mientras las regias se preocupan tanto por su look, las rotas hambrientas devoran la comida: "[...] había tanta comida; veinte pavos, champañas por cajas, ensaladas y helados de todos los sabores. Pero estas rotas tan hambrientas, no dejaron nada, se lo comieron todo. Como si viniera una guerra" (13). La escena nos recuerda la imagen del banquete, elaborada por Bahktin en Rabelais y su mundo, en la que el acto de comer permite que el cuerpo se autorice y conquiste su ambiente. A través del festejo, 
las rotas superan las intimidaciones de las regias y permutan, si solo por un instante, el "espejo desnutrido de nuestras locas" (22). Dicha imagen, según Lemebel, no puede competir con el estereotipo importado de "mister gay", definido por los músculos exagerados y una dieta del primer mundo. El montón de huesos de los restos del pavo, los cuales utilizan para construir un monumento, cubierto con la bandera nacional, predicen la imagen del cuerpo debilitado, y finalmente conquistado, que posee el aquejado por el SIDA y compara la escena globalizada de la moda con las expectativas poco realistas del cuerpo humano.

Esa noche heterotópica permite una fusión de clases sociales dentro de las propias subculturas. Las circunstancias únicas de este encuentro se iluminan aún más por la fragilidad de la vida cuando el lector se entera de la contracción del SIDA por parte de la anfitriona, Chililou, cuya tragedia en parte se debe a su amor y necesidad por la moda, que la encegueció tanto que no vio el carácter oneroso del extranjero al que se entregó sin protección por los "tantos billetes, tanta plata, tantos dólares que pagaba ese gringo" (19). Dentro de los sueños consumidores de la Chili, ese verde abanico atrayente dolarizado que se convertiría en "tanto maquillaje, máquinas de afeitar y cera depilatoria. Tantos vestidos y zapatos nuevos para botar los zuecos pasados de moda. Eran tantos sueños apretados en el manojo de dólares" (19). Ese fragmento parangona la enfermedad en sí con los propios artículos de ropa y productos que la loca emplea para construir su imagen, mientras, a la vez, alude a la "invasión extranjera", el neoliberal poder del dólar que adormece el futuro del país.

A pesar de que Lemebel señala la responsabilidad de la loca en cuanto a su contagio por puro anhelo de la moda, el autor subvierte las indeseables manifestaciones físicas del SIDA. En cambio, el escritor equipara el cuerpo sidoso de una de las regias, la Pilola, con el de una modelo de alta costura y alaba su dieta eficaz en el caso de una de las regias ${ }^{2}$ :

Esa sombra, es una delicada venda de celofán que enlaza la cintura de la Pilola Alessandri, apoyando su cadera maricola en el costado derecho de la mesa. Ella se compró la epidemia en Nueva York, fue la primera que la trajo en exclusiva, la más auténtica, la recién estrenada moda gay para morir. La última moda fúnebre que la adelgazó como ninguna dieta lo había conseguido. La dejó tan flaca y pálida como una modelo del Vogue, tan estirada y chic como un suspiro de orquídea. El SIDA le estrujó el cuerpo y murió tan apretada, tan fruncida, tan estilizada y bella en la economía aristócrata de su mezquina muerte (16).

La fascinación de esta subcultura con el cuerpo rápidamente transformándose, resalta el valor de la hegemonía de las medidas extremas que se pueden esperar para alcanzar dichas imágenes culturales poco realistas que

2 Otro ejemplo se encuentra en "La Regine de aluminios el mono": "Tan flaca que está usted Regine. ¿Qué régimen está siguiendo?" (26). 
con bastante frecuencia se requieren en la moda. En este fragmento notamos el desplazamiento desde la revista nacional Paula a la internacional Vogue, un paralelo de las astillas aumentadoras de la globalización, un ensanchado mercado liberal que psicológicamente invade la conciencia colectiva chilena, y de manifestación física, que contamina el cuerpo a través de la epidemia sidosa. Debido a dichas mediaciones y al definir las reacciones corporales en contra de estos valores estéticos, el autor irónicamente "promueve" la enfermedad como un recurso para alcanzar dicha imagen corporal idealizada e ilusoria.

En directo diálogo con estas representaciones de la moda, las aspiraciones de una imagen de alta costura, se encuentra el fenómeno de la ropa usada, un tema de amplio interés entre teóricos como Nelly Richard, quien reconoce la función organizadora de la ropa en cuanto a las identidades culturales y los discursos de clase y sexualidad (111). El propósito ordenador de la moda cambia por completo con la introducción de la ropa usada, que como anota Richard en el caso chileno:

La comercialización masiva de la ropa usada durante los últimos años en Chile parecerá haber multiplicado las confusiones entre lo nacional y lo importado, lo local y lo transnacional, hasta sumergir las fachas vestimentarias de los pobres urbanos en la dislexia de estas prendas sacadas de códigos que se entrecruzan debido a la baratura y la casualidad de las mezclas: restos bastardos de vestimentas importadas, saldos baratos de la serie-moda de las metrópolis son reensamblados por cuerpos populares que deambulan con ellos armando el espectáculo visual de un collage de identidad sin coherencia de estilo ni unidad de vocabulario (111-12).

Las posibilidades para identidades posmodernas, sin el ojo codificador del mercado - los anuncios, las vitrinas- abundan con el surgimiento de la ropa de segunda mano. Si pensamos en términos de Barthes, es un alejamiento de la prenda interminable, el endless garment que según el filósofo en The Fashion System esa prenda without end is proffered through a text which is itself unending. This total garment must be organized, i.e., cut up and divided into significant units, so that they can be compared with one another and in this way reconstitute the general signification of Fashion (42). De hecho, con dicho fenómeno se crea un nuevo espacio para la creatividad y un aumento de combinaciones tanto en las clases altas como en las comunidades travestis (Richard, 114-122). En el caso travesti chileno se imita un re-reflejo de imágenes -de mujer y de los travestis de Nueva York- teniendo como resultado una nueva identidad creativa. Según la teórica mencionada, "[...] el travesti chileno poblacional burla el patrón de las identidades sexuales normativas a la vez que desidealiza la femineidad de alta costura con su sátira vulgar que lleva lo copiado a desentonar violentamente con el original, poniendo así en crisis el calce imitativo del doblaje al que recurren -perfeccionistamente- los travestis de Nueva York" (123). Con el juego antagónico centro/periferia, primer/tercer mundo, original/simulacro, Lemebel clava una aguja incómoda en la hegemónica tela dialéctica. 
Para reconsiderar este fenómeno, Lemebel regresa abiertamente al centro del propio discurso, a Nueva York, en su crónica "La moda marchita", trasladando su eje desde la enfermedad en Latinoamérica a los Estados Unidos. Dianna Palaversich reconoce la envergadura de esta táctica: "Al atribuir el origen de la enfermedad a los Estados Unidos Lemebel invierte la narrativa del SIDA estadounidense, que atribuye la contaminación a un agente externo, africano y haitiano. Lemebel coloca el centro de la infección en el país más poderoso del primer mundo, donde esta enfermedad se vuelve símbolo potente de la decadencia de la sociedad capitalista" $(261)^{3}$. El autor Ileva al lector a los Estados Unidos de 1987, donde se encuentra con "El proyecto de nombres" (el propio título de esta crónica con el apartado "un mapa sentimental", entre otros) o "Quilt", que con la antigua ropa de los fallecidos unifica la memoria individual con una colectiva a través de la confección de una arpillera conmemorativa. Este mapa, como lo identifica Lemebel, traspasa varias etnias y culturas y forma "Cruces transculturales que se encuentran en el roce de lija que une estos ajuares. Nombres rutilantes en hilos de oro como Foucault, Hudson, Liberace, Nureyev, se saludan con el anónimo 'Louis, ANOCHE NO PARECÍA QUE IBA A LLOVER', 'MICHAEL, NO ALCANCÉ A DECÍRTELO', 'CARLOS, EL TIEMPO FUE, FUE UN TIEMPO"' (92). La reapropiación de la ropa para Lemebel lleva un mensaje lleno, y a la vez vacío, del cuerpo enfermo: "Al igual que banderas de naufragio, los Quilt's van parchando el corazón con los restos indumentarios que alguna vez erotizaron el cuerpo de castigo" (92). Este arte popular -quizás reminiscente de las propias arpilleras diseñadas durante los años de la dictadura- visualmente se junta para elaborar la aniquilación de la epidemia del SIDA.

Dentro de la misma crónica, Lemebel yuxtapone esa sentimentalidad consciente de los seres queridos del fallecido, con la inconsciencia dirigida por la avaricia del consumidor hacia la ropa usada de los difuntos. Según el cronista, "Así fuera un gran supermarket, un vestuario posmortis de telas y ropas con poco uso, reciclada como evidencia de la plaga permeada a través de la moda" (93). Nelly Richard reconoce el "rechazo inconsciente" de la ropa usada por "haber sido previamente habitada por otro cuerpo" y "contener todos los olores, manchas que delaten los accidentes de la piel de un cuerpo portador de enfermedades cutáneas" (120). El mismo autor no libera a su lector de dicha experiencia abyecta que según Julia Kristeva, atrae simultáneamente tanto como repugna ${ }^{4}$. Al contrario, nos obliga a enfrentar lo "descolorido por el sudor bajo la axila", los "paños desvaídos, donde el color perdió su brillo con el roce clínico" (93). Se incluye la verdadera vida diaria de los afligidos por las propias prendas con descripciones detalladas: "Un buzo deportivo ocupado en una corta carrera, una acezante gimnasia que terminó en desmayo" o "El terno Oscar de la Renta que le compró la familia para que el enfermo muriera uniformado, para que en el último adiós pareciera hombre, ahorcado por la corbata italiana" (93). La moda y el cuerpo enfermo concurren con posibilidades grotescas para una doble

\footnotetext{
3 Palaversich lo lee como una versión de la leyenda negra. En Reinas de otro cielo: modernidad y autoritarismo en la obra de Pedro Lemebel (2004), Jean Franco también reconoce las contribuciones de Lemebel en cuanto a un acercamiento alternativo de la historia, el que "names both victims and deaths, and gives homosexuality a political space" (17).

4 Véase Powers of Horror para una elaboración de lo abyecto según Kristeva.
} 
lectura de "pieles", como cuero y carne humana: "[...] un vértigo de pasarelas donde caen las pieles sidadas de la moda" (93). El lector se enfrenta con "Un derrumbe de algodones y terciopelos, que en su rebaja de luto se convierten en el look agónico, en el look de un postrero desfile, donde se traviste la falta con los fragmentos que encintaron la vida" (93). Esta elaboración, enriquecida con léxico indumentario, además incluye la inserción del anglicismo look, una acumulación toda inclusiva del exterior que implica una reacción clasificadora por parte del observador. Para formar dicha opinión, el espectador implementa la forma verbal to look. Asimismo, la crónica de Lemebel llama al lector a contribuir más activamente al legado del difunto, que una simple relación voyerista.

En Fashion on the Edge: Spectacle, Modernity and Deathliness (2003) Caroline Evans aplica las teorías marxistas de mercancía -the value of a commodity represents nothing but the quantity of labor embodied in it- a la experimentación de los diseñadores en cuanto a "envejecer" telas nuevas para que parezcan usadas (261). La autora reconoce la paradoja en la convergencia de haute couture que suele distanciarse de la producción masiva con la imagen que

[...] remains locked, like the foraging of the nineteenthcentury rag picker, into the very capitalist system whose cycles of production and consumption it might be seen to be criticizing (262). De esta misma manera, estos consumidores lembelianos se convierten en los ropavejeros cuando ahorrativamente compran en el mercado de los "posmortis", y con una mórbida vuelta de rosca de la implementación de "reciclaje", deben, a la vez, tener presente en su propia conciencia social los acontecimientos cotidianos que esta ropa sufrió, tanto por los límites corporales como por los sexuales. Lemebel inquietamente incomoda al consumidor de la naturaleza fantasmagórica de las prendas, de manera que son "Ropas fantasmas, escondiéndose, flotando, jugando a camuflarse en el clóset con la ropa de los vivos", que "Después de tantas lágrimas se empeña en reaparecer en la arqueología trapera de sus vestigios" (94). Este retrato del autor del inconsciente reciclaje de la ropa de los difuntos, clama con el perpetuo silencio de esta enfermedad tabú, y asimismo, la muerte que la acompaña.

De una forma más coquetona la ropa usada también brilla y se ilumina en la crónica "Nalgas lycra, sodom disco" en la que Lemebel pinta el fenómeno de la disco gay, una esfera cerrada, flotando entre el caos de la, a veces, mala intención de la contaminación -"Sus artimañas para contagiar a medio Santiago porque no quería irse sola" (53) - y la organización perfecta donde "(...) una filosofía de camuflaje viril que va uniformando, a través de la moda, la diversidad de las homosexualidades locales" (53). Las mismas descripciones plantean una identidad no completada por parte de los asistentes: "Casi reinas, si no fuera por esos hilvanes rojos de la basta apurada. Casi estrellas, de no ser por la marca falsa del jean's tatuada a media nalga. 
Algunas casi jóvenes, en la ropa sport clara y las zapatillas Adidas, envueltas en la primavera color pastel y ese rubor prestado del colorete" (51). La repetición de "casi", con su toque sarcástico, alude a dichas identidades forzadas en construcción, estos performances que dependen -al menos a primera vista- de la moda, de la categorización a base de la apariencia. Nos permite una mirada que no reside en lo idealizado ni utópico, en la que no todos están cómodos con su sexualidad, como por ejemplo el "oficinista de corbata que preocupado mira la entrada por si aparece un compañero de trabajo" (52). A pesar de estas luchas inseguras y simultáneas, ese espacio designado aplaude una sexualidad escogida, celebrada y destacada, más que nada por las elecciones de vestimenta:

El bar de la disco es para cruzar miradas y exhibir la oferta erótica en las marcas de la ropa preferida. Las pintas de segunda mano que ofrece la ropa americana. Así, el bordado Levis asegura una cola de lujo, un par de nalgas vaqueras infladas por la moda, fibrosas en el gesto tenso de apoyar los cachetes en la barra. Casi masculinas, si no fuera por la costura del jean's hundida en el tajo azulado. De no ser por el planchado y ese olor a soft, a detergente. A demasiada limpieza, como dando disculpas por ser así, explicando la homosexualidad en el borlado aroma que enmarca los gestos. Si no fuera por esa nube densa del perfume coliza; la adicción por el Paloma Piccaso, el Obsession for men de Calvin Klein, el Orfeo Rosa de Paco Colibrí. Si no fuera por todos esos nombres que emanan del aeróbico sopor, pasarían por hombres heterosexuales demasiado amigos, por machitos borrachos baboseando al compadre (52).

Este código de prendas, hecho en parte por el uso de la ropa americana, celebra la sexualidad. A través de los olores, el maquillaje y las marcas de moda, el autor no simplemente encaja la identidad homosexual dentro de la heteronormatividad, sino que la mantiene aparte, mientras simultáneamente señala los gestos comunes que los unen. La variedad de los "casi" refuerza la dificultad de la categorización, de la identidad en progreso, marcada pero a la vez no completamente delimitada por la moda.

En la última crónica que exploraremos para este estudio, la ropa usada o lo reapropiado llega a extremos creativos con la figura de Madonna, que alumbra la importancia de la cultura popular -entretejida con la estéticaen términos de la reapropiación de artículos disponibles para copiar y en el proceso de crear una imagen. Aunque el autor relata una serie de figuras latinoamericanas a lo largo de sus crónicas, entre ellas María Félix, Violeta Parra y Eva Perón, por nombrar algunas, se destaca la importancia de figuras importadas que acompañan el fenómeno neoliberal a través de inyecciones de Madonna, Claudia Schiffer y la ubicua Elizabeth Taylor. En la crónica "La muerte de Madonna" se reseña la muerte de la versión chilena loca que mantuvo una obsesión -"sin pelo ni dientes"- por la estrella pop (34). Por un lado, la Madonna abusa de su cuerpo para llegar a la imagen deseada de su ídolo, a pesar de las burlas de sus comadres: "[...] Con el agua oxigenada 
se le quemaron las raíces y el cepillo quedaba lleno de pelos. Se le caía a mechones. Nosotros le decíamos que parecía perra tiñosa, pero nunca quiso usar peluca" (33). El significado de ese pelo perdido, tan propio de la loca, se puede clarificar a través de la relectura de Elizabeth Grosz y sus ideas kristeveanas de lo abyecto en la que, las partes desmontables del cuerpo, como el pelo, retain something of the cathexis and value of a body part even when they are separated from the body. There is still something of the subject bound up with them, which is why they are objects of disgust, loathing and repulsion as well as envy and desire (81). Con la negación de Lemebel hacia dicha abyección, hilado con un humor macabro, el autor desconstruye la identidad pop norteamericana y presenta al lector con una cabeza casi calva, como un lienzo listo para la recreación. La Madonna mapuche expresa su creatividad con reapropiaciones de ropa o pedazos de ella: "Y ella imitando a la Madonna con el pedazo de falda, que era un chaleco beatle que le quedaba largo. Un chaleco canutón, de lana con lamé, de esos que venden en la ropa americana. Ella lo arremangaba con un cinturón y le quedaba una regia minifalda. Tan creativa la cola, de cualquier trapo inventaba un vestido" (34). La capacidad innovadora de la loca que no se debilita por la propia pobreza o falta de vestuario se contrasta con la gravedad en cuanto a la inconsciencia lingüística de ella: "Repetía como lora las frases en inglés, poniéndole el encanto de su cosecha analfabeta" (34). Entonces, esta Madonna mapuche, según las demás locas, no solo se entrega como una esclava a la tiranía de la moda -en las palabras de Susan Bordo-, sino a todo lo que ella conlleva. Como el inconsciente consumidor/ropavejero que hurga por los clósets de los fallecidos, las representaciones de esta versión alternativa de la ídolo Madonna expone los peligros de simplemente repetir las letras extranjeras, de internalizarlas, y urge una confrontación activa de los valores culturales a veces latentemente impuestos.

Mediante la dialéctica de la moda -un medio cultural que llega a un público vasto y diverso- Lemebel se dirige a la realidad callada del SIDA. Con las crónicas juguetonas del autor, las locas alcanzan una belleza efímera, un estilo comparable con el de una estrella del cine o con una portada de revista. Con algo visual tan cotidiano como la moda, Lemebel pone en cuestión la propia participación del consumidor, su incansable búsqueda para conseguir su look, la que con frecuencia no toma en conciencia el dónde ni el cómo se consigue una prenda en dicho mercado globalizado y distanciado de la propia fuente de producción. A la vez, la creatividad de las locas se luce, por solo un instante, en un desfile distinto que rediseña otras posibilidades, cuestionando y empoderando a la sociedad chilena.

\section{Obras citadas}

Bakhtin, Mikhail. Rabelais and his world. Trans Hélène Iswolsky. Indiana: U de Indiana $\mathrm{P}, 1984$.

Barthes, Roland. The fashion system. Trans Matthew Ward y Richard Howard. Berkeley y Los Ángeles: U de California P, 1983.

Bordo, Susan. Unbearable weight: feminism, western culture, and the body. Berkeley: U de California P, 1993.

Evans, Caroline. Fashion on the edge: spectacle, modernity and deathliness. New Haven: Yale UP, 2003. 
Franco, Jean. Reinas de otro cielo: modernidad y autoritarismo en la obra de Pedro Lemebel. Santiago: LOM, 1994.

Grosz, Elizabeth. Volatile bodies: toward a corporeal feminism. Bloomington: $U$ de Indiana P, 1994.

Kristeva, Julia. Powers of horror. Trans Leon S. Roudiez. New York: Columbia UP, 1982.

Lemebel, Pedro. Loco afán: crónicas de sidario. Santiago: LOM, 1996.

Mateo del Pino, Ángeles. "Inestable equilibrio: entre el deseo y la muerte o El mismo, el mismo loco afán". Desdén al infortunio: sujeto, comunicación y público en la narrativa de Pedro Lemebel. Ed Blanco, Fernando A. y Juan Poblete. Santiago: Editorial Cuarto Propio, 2010.

Palaversich, Dianna. "El cuerpo agredido de la homosexualidad proletaria y Loco afán de Pedro Lemebel". Desdén al infortunio: sujeto, comunicación y público en la narrativa de Pedro Lemebel. Ed Blanco, Fernando A. y Juan Poblete. Santiago: Editorial Cuarto Propio, 2010.

Richard, Nelly. Residuos y metáforas: (ensayos de crítica cultural sobre el Chile de la transición). Santiago: Cuarto Propio, 1998.

Svendsen, Lars. Fashion: a philosophy. Trans John Irons. Londrés: Reaktion, 2006.

Torres Cautivo, Ximena. "¿Qué ha sido del SIDA?", Paula. Junio (1987): 67-9. 